\title{
Normalization of Plus Size and the Danger of Unseen Overweight and Obesity in England
}

\author{
Raya Muttarak (1D ${ }^{1,2}$
}

Objective: This study aimed to investigate trends and sociodemographic factors underlying weight misperception in adults with overweight and obesity in England.

Methods: This study used descriptive and logistic regression analyses based on a pooled nationally representative cross-sectional survey, Health Survey for England, for the years 1997, 1998, 2002, 2014, and 2015 of individuals with $\mathrm{BMI} \geq 25$ ( $n=23,459)$. The main outcomes were (1) weight misperception and (2) weight-loss attempts as well as the associations with demographic and socioeconomic characteristics and health status.

Results: The proportion of individuals with overweight and obesity misperceiving their weight status increased over time between 1997 and 2015 (37\% to 40\% in men; 17\% to 19\% in women). There were socioeconomic disparities in the misperception of weight status, with lower-educated individuals from poorer-income households and members of minority ethnic groups being more likely to underestimate their weight. Those underestimating their overweight and obesity status were $85 \%$ less likely to try to lose weight compared with people who accurately identified their weight status.

Conclusions: The upward trend in underassessment of overweight and obesity status in England is possibly a result of the normalization of overweight and obesity. Obesity prevention programs need to consider differential sociodemographic characteristics associated with underassessment of weight status.

Obesity (2018) 26, 1125-1129. doi:10.1002/oby.22204

\section{Introduction}

The year 2018 started with a fresh launch of new plus-size women's wear from Marks \& Spencer, one of the leading fashion retailers in the United Kingdom (1). The new fashion range is elegantly called "Curve," a more flattering term than "plus," aiming to minimize the negative image of plus-size fashion. By introducing a new design and styling tailored for plus-size customers and using carefully selected fabrics complementing fuller figures, Curve primarily contributes to promoting body positivity. While this type of bodypositive movement helps reduce stigmatization of larger-sized bodies, it can potentially undermine the recognition of being overweight and its health consequences.

Seeing the huge potential of the fuller-sized fashion market, plus-size retailers may have indeed contributed to the normalization of stigma associated with overweight and obesity. Not only have clothes for larger-sized bodies been repackaged to flatter curvy women (2), changing the labeling of clothes sizes can distort consumers' perceptions of size (3). In the United Kingdom and United States, "vanity sizing," or size inflation whereby clothing manufacturers label the clothes with sizes smaller than the actual cut, is widely practiced. Although purchasing clothes with smaller size labels helps promote a positive self-related mental imagery and self-esteem (4), vanity sizing can potentially lead to the misperception of weight status and consequently undermine action to reduce weight (5).

Furthermore, according to the visual normalization theory, as larger body weights have become more common, overweight and obesity have become normalized, leading to underestimation of weight status (6). Indeed, both epidemiological data and experimental studies have shown that exposure to obesity not only increases the acceptability of heavier body weights but also influences body shape preferences $(7,8)$. While it remains debatable whether the correct perception of one's own weight has a beneficial effect on health (9), awareness of overweight status is a prerequisite for weight-loss attempts (10). With more than one in four adults aged 15 and older

${ }^{1}$ Wittgenstein Centre for Demography and Global Human Capital (IIASA, VID/ÖAW, and WU), International Institute for Applied Systems Analysis, Laxenburg, Austria. Correspondence: Raya Muttarak (muttarak@iiasa.ac.at) ${ }^{2}$ School of International Development, University of East Anglia, Norwich, UK.

See Commentary, pg. 1115.

Disclosure: The author declared no conflict of interest.

Received: 19 February 2018; Accepted: 6 April 2018; Published online 22 June 2018. doi:10.1002/oby.22204

This is an open access article under the terms of the Creative Commons Attribution-NonCommercial License, which permits use, distribution and reproduction in any medium, provided the original work is properly cited and is not used for commercial purposes. 
classified as having clinical obesity in the United Kingdom (11), underassessment of overweight can pose a serious global burden to health and health expenditure $(12,13)$.

To this end, this study aims to explore the trends in perceived weight status among the English adult population with overweight or obesity. The study also investigates demographic and socioeconomic factors associated with self-perception of weight status, particularly weight underassessment and attempts to lose weight.

\section{Methods}

\section{Data and participants}

Using a multistage stratified sampling design, the Health Survey for England is a nationally representative annual survey designed to provide regular information on the health of people in England. Data collection involves both face-to-face interviews and a selfcompletion questionnaire. Apart from information on health and health-related behaviors, information on socioeconomic factors, physical measurements, and biological samples is also collected. This allows for an estimation of the prevalence of risk factors and behaviors associated with specified health conditions.

BMI is calculated based on weight and height information recorded by trained nurses (kilograms divided by meters squared). These BMI data are considered to be the major source of health statistics to inform policies on obesity in the United Kingdom (14). The weight status categories associated with BMI ranges are defined based on the following World Health Organization guidelines: (1) BMI $<18.5$ is classified as underweight, (2) BMI of 18.5 to 24.9 is normal weight, (3) BMI of 25.0 to 29.9 is overweight, and (4) $\mathrm{BMI} \geq 30.0$ is obesity.

In order to assess trends in self-perception of weight status, the analysis was based on pooled data from 5 years (1997, 1998, 2002, 2014, 2015) of the Health Survey for England, which contained a question on weight perception. The pooled data had a sample size of 77,424 . Participants were excluded from the analysis if they were younger than 16 years of age $(n=26,493)$ or were missing BMI measures $(n=5,043)$, information on their weight perception ( $n=3,859)$, information on whether they were trying to change weight $(n=128)$, or information on ethnicity $(n=9)$. This study focuses on participants with $\mathrm{BMI} \geq 25$, thus bringing the final analytic sample size to 23,459 .

\section{Measures}

The primary outcome of interest was underassessment of overweight and obesity status. This variable was constructed based on BMI measures and the question on self-perception of one's own weight. Respondents were asked, "Given your age and height, would you say that you are..." and were provided with the following four options: (1) about the right weight, (2) too heavy, (3) too light, and (4) not sure. Underassessment of overweight and obesity status was a binary variable coded 1 when individuals with BMI $>25$ described themselves as too light or about the right weight, and they were coded 0 otherwise.

The secondary outcome was whether the participants were trying to lose weight. This variable was based on the survey question that

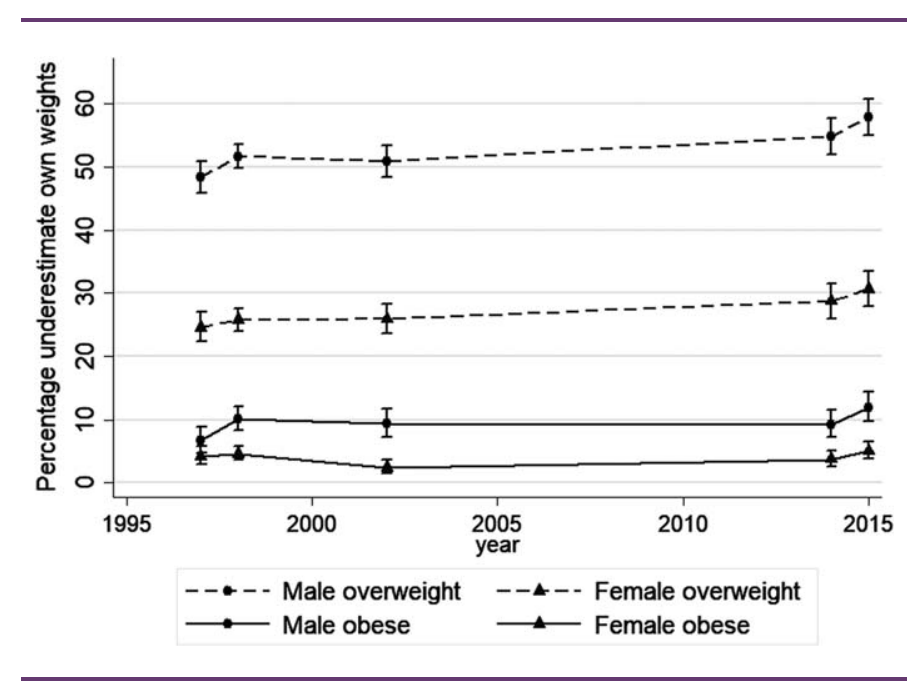

Figure 1 Percentage underestimating weight status by sex and year of survey with error bars representing 95\% confidence intervals. Source: pooled data from Health Survey for England (1997, 1998, 2002, 2014, 2015).

asks whether the respondent is currently trying to lose weight, trying to gain weight, or not trying to change weight. Those who answered that they were currently trying to lose weight were coded 1, and they were coded 0 otherwise.

\section{Statistical analyses}

Stata software version 13.0 (StataCorp LLC, College Station, Texas) was used for statistical analysis. Multivariate logistic regression analyses were conducted to evaluate the relationship between years of survey, BMI status, and the outcome variables. All models were adjusted for age, sex, ethnicity, education, household income, and self-rated health.

\section{Results}

A normalization of overweight and obesity has become widespread in England. Among individuals with overweight or obesity, a substantial proportion, $38.5 \%$ of men and $17.2 \%$ of women, perceived their weight as about the right weight. Figure 1 suggests that the number of individuals with overweight underassessing their weight increased over time, from $48.4 \%$ to $57.9 \%$ in men and $24.5 \%$ to $30.6 \%$ in women between 1997 and 2015. Similarly, among individuals classified as having obesity, the proportion of men misperceiving their weight as about the right weight in 2015 doubled that of 1997 (6.6\% vs. $12.0 \%)$.

Table 1 presents characteristics of the participants by weight underassessment and attempts to lose weight. Approximately $40 \%$ of the participants were aged 16 to 44 years, the majority were white participants, and about one-sixth reported having a degree qualification. Among the sample with BMI $>25$, about two-thirds were classified as having overweight and one-third with obesity. The majority (72.6\%) reported their general health as good or very good.

Generally, men were more likely than women to underestimate their overweight or obesity status $(38.8 \%$ vs. $16.8 \%)$ and consequently 
TABLE 1 Characteristics of sample with $\mathrm{BMI} \geq 25$ and statistical tests of group differences

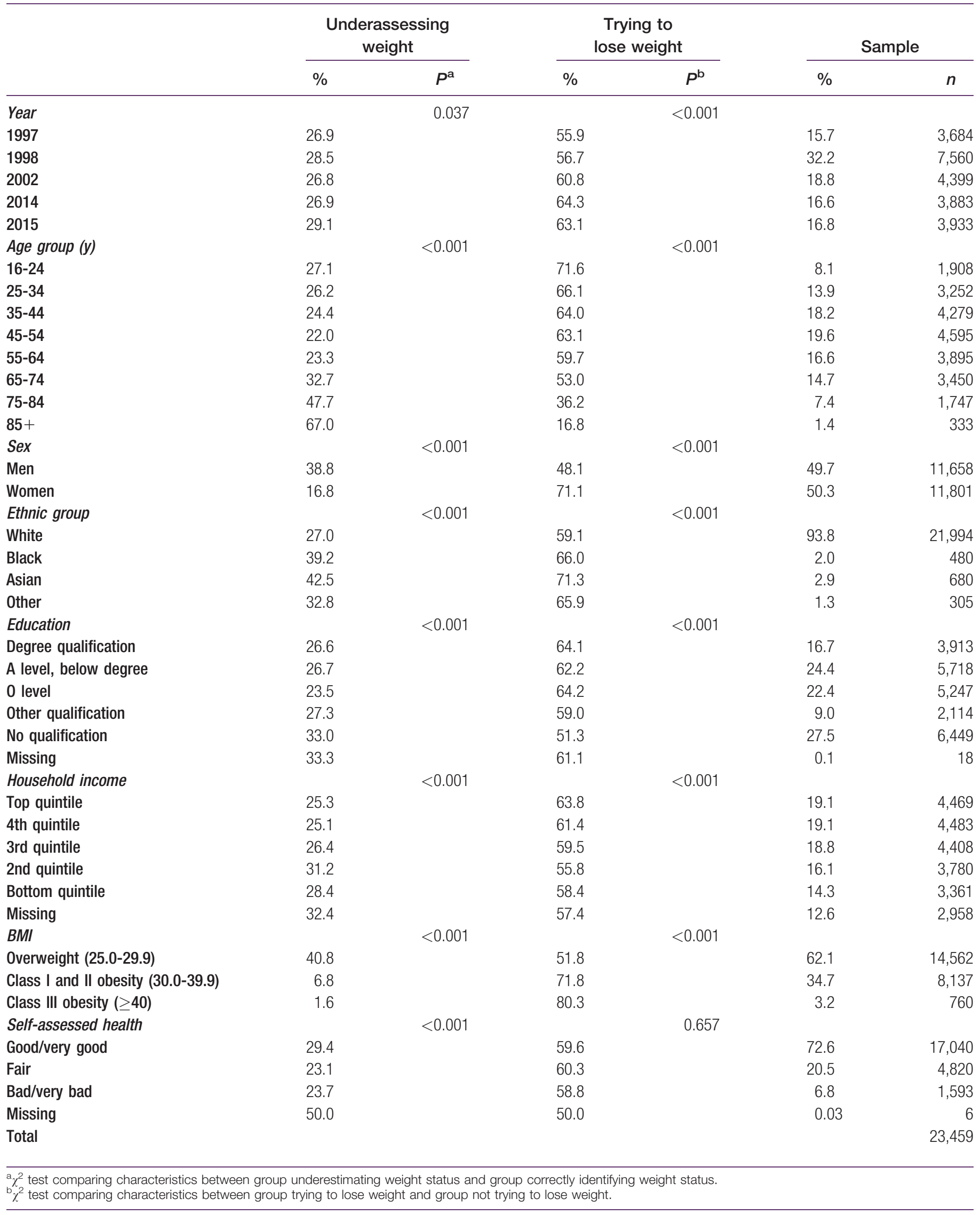


TABLE 2 Odds ratio of weight underestimation and weight-loss attempts and $95 \%$ Cls in multivariable models of logistic regression

\begin{tabular}{|c|c|c|c|c|}
\hline & \multicolumn{2}{|c|}{ Underassessing weight } & \multicolumn{2}{|c|}{ Trying to lose weight } \\
\hline & OR & $95 \% \mathrm{Cl}$ & OR & $95 \% \mathrm{Cl}$ \\
\hline Underestimate weight status & & & $0.155^{\mathrm{a}}$ & $0.144-0.167$ \\
\hline \multicolumn{5}{|l|}{ Year (ref: 1997) } \\
\hline 1998 & $1.098^{\mathrm{b}}$ & $0.992-1.216$ & $1.087^{\mathrm{b}}$ & $0.992-1.191$ \\
\hline 2002 & $1.122^{\mathrm{b}}$ & $0.999-1.260$ & $1.117^{\mathrm{c}}$ & $1.006-1.240$ \\
\hline 2014 & $1.197^{d}$ & $1.061-1.351$ & $1.543^{\mathrm{a}}$ & $1.383-1.721$ \\
\hline 2015 & $1.425^{\mathrm{a}}$ & $1.264-1.607$ & $1.498^{\mathrm{a}}$ & $1.343-1.671$ \\
\hline \multicolumn{5}{|l|}{ Age group (y) (ref: 16-24) } \\
\hline $25-34$ & 0.991 & $0.854-1.150$ & $0.693^{\mathrm{a}}$ & $0.600-0.800$ \\
\hline $35-44$ & $0.848^{\mathrm{C}}$ & $0.735-0.978$ & $0.586^{\mathrm{a}}$ & $0.511-0.673$ \\
\hline $45-54$ & $0.766^{\mathrm{a}}$ & $0.663-0.885$ & $0.538^{\mathrm{a}}$ & $0.469-0.617$ \\
\hline $55-64$ & 0.885 & $0.763-1.026$ & $0.478^{\mathrm{a}}$ & $0.416-0.551$ \\
\hline $65-74$ & $1.352^{\mathrm{a}}$ & $1.164-1.571$ & $0.436^{\mathrm{a}}$ & $0.377-0.503$ \\
\hline $75-84$ & $3.113^{\mathrm{a}}$ & $2.624-3.693$ & $0.247^{\mathrm{a}}$ & $0.209-0.292$ \\
\hline $85+$ & $7.078^{\mathrm{a}}$ & $5.228-9.583$ & $0.111^{\mathrm{a}}$ & $0.079-0.156$ \\
\hline \multicolumn{5}{|l|}{ Sex (ref: men) } \\
\hline Women & $0.273^{\mathrm{a}}$ & $0.255-0.293$ & $2.092^{\mathrm{a}}$ & $1.966-2.227$ \\
\hline \multicolumn{5}{|l|}{ Ethnic group (ref: white) } \\
\hline Black & $3.747^{\mathrm{a}}$ & $2.975-4.720$ & $1.492^{\mathrm{a}}$ & $1.193-1.866$ \\
\hline Asian & $2.608^{\mathrm{a}}$ & $2.166-3.140$ & $2.406^{\mathrm{a}}$ & $1.972-2.934$ \\
\hline Other & $1.711^{\mathrm{a}}$ & $1.290-2.269$ & $1.269^{b}$ & $0.965-1.670$ \\
\hline \multicolumn{5}{|l|}{ Education (ref: degree) } \\
\hline A level, below degree & $1.170^{\mathrm{d}}$ & $1.052-1.302$ & 0.944 & $0.855-1.042$ \\
\hline 0 level & $1.181^{\mathrm{d}}$ & $1.054-1.322$ & 0.920 & $0.830-1.020$ \\
\hline Other qualification & $1.337^{\mathrm{a}}$ & $1.155-1.548$ & 0.942 & $0.825-1.075$ \\
\hline No qualification & $1.839^{\mathrm{a}}$ & $1.632-2.071$ & $0.787^{\mathrm{a}}$ & $0.705-0.878$ \\
\hline Missing & 1.733 & $0.548-5.477$ & 0.979 & $0.316-3.032$ \\
\hline \multicolumn{5}{|l|}{ Household income (ref: top quintile) } \\
\hline 4th quintile & 1.029 & $0.923-1.146$ & $0.869^{d}$ & $0.787-0.959$ \\
\hline 3rd quintile & 1.069 & $0.955-1.197$ & $0.849^{\mathrm{d}}$ & $0.766-0.940$ \\
\hline 2nd quintile & $1.316^{\mathrm{a}}$ & $1.165-1.486$ & $0.831^{d}$ & $0.744-0.929$ \\
\hline Bottom quintile & $1.307^{\mathrm{a}}$ & $1.149-1.485$ & $0.808^{\mathrm{a}}$ & 0.719-0.907 \\
\hline Missing & $1.323^{\mathrm{a}}$ & $1.167-1.500$ & $0.809^{\mathrm{a}}$ & $0.720-0.909$ \\
\hline \multicolumn{5}{|l|}{ BMI (ref: overweight [25.0-29.9]) } \\
\hline Class I and II obesity (30.0-39.9) & $0.090^{\mathrm{a}}$ & $0.082-0.099$ & $1.315^{\mathrm{a}}$ & $1.227-1.409$ \\
\hline Class III obesity $(\geq 40)$ & $0.030^{\mathrm{a}}$ & $0.017-0.053$ & $1.476^{\mathrm{a}}$ & $1.218-1.788$ \\
\hline \multicolumn{5}{|c|}{ Self-assessed health (ref: good/very good) } \\
\hline Fair & $0.685^{\mathrm{a}}$ & $0.625-0.750$ & 1.000 & $0.925-1.082$ \\
\hline Bad/very bad & $0.721^{\mathrm{a}}$ & $0.621-0.837$ & 1.013 & $0.894-1.148$ \\
\hline Missing & 4.403 & $0.677-28.634$ & 1.092 & $0.166-7.177$ \\
\hline Constant & $0.682^{\mathrm{a}}$ & $0.573-0.813$ & $3.163^{\mathrm{a}}$ & $2.668-3.750$ \\
\hline Observations & \multicolumn{2}{|c|}{23,459} & \multicolumn{2}{|c|}{23,459} \\
\hline Log likelihood & \multicolumn{2}{|c|}{$-10,647$} & \multicolumn{2}{|c|}{$-12,763$} \\
\hline DF & \multirow{2}{*}{\multicolumn{2}{|c|}{30}} & \multicolumn{2}{|c|}{31} \\
\hline \multirow{2}{*}{\multicolumn{3}{|c|}{ Pseudo $R^{2}$}} & & \\
\hline & 0.232 & & 0.193 & \\
\hline $\begin{array}{l}a p<0.001 \\
\mathrm{p} p<0.1 \\
\mathrm{p}<<0.05 \\
\mathrm{~d}<<0.01 \\
\mathrm{DF} \text {, degrees of freedom; OR, odds ratio. }\end{array}$ & & & & \\
\hline
\end{tabular}


were less likely to try to lose weight $(48.1 \%$ vs. $71.1 \%)$. The proportion underestimating their weight status was higher among overweight individuals compared with those with obesity $(40.8 \%$ vs. $8.4 \%$ ). Correspondingly, only about half of overweight individuals were trying to lose weight compared with over two-thirds of those with obesity. Table 1 also shows disparities in underassessment of weight status and attempts to lose weight by demographic and socioeconomic characteristics.

Table 2 presents adjusted odds ratios (ORs) with 95\% CIs based on multivariate logistic regression estimates for underassessment of weight status and attempts to lose weight. The odds of misperception of weight status significantly declined with the level of education and income. The odds of underestimating overweight and obesity among individuals with no qualification was 1.8 times higher (95\% CI: 1.63 2.10) than those with degree qualifications. Likewise, individuals in the bottom-income quintile were 1.3 times (95\% CI: $1.15-1.49$ ) more likely to misperceive their weight compared with those in the topincome quintile. Members of minority ethnic groups also had higher odds of underestimating their weight compared with the white population (black OR 3.75, 95\% CI: 2.98-4.72; Asian OR 2.61, 95\% CI: 2.17-3.14; other ethnic group OR 1.71, 95\% CI: 1.30-2.27).

Underassessment of weight status was negatively associated with attempts to lose weight, with $85 \%$ reduction in the odds of trying to lose weight (OR 0.16, 95\% CI: 0.14-0.17). Attempts to lose weight among individuals with overweight and obesity were also associated with socioeconomic characteristics, with individuals with no degree qualification and in lower-income quintiles being less likely to try to lose weight. Compared with the white population, members of minority groups were more likely to try to lose weight (black OR $1.49,95 \%$ CI: 1.19-1.87; Asian OR 2.41, 95\% CI: 1.97-2.93).

\section{Discussion}

Despite being highlighted by Johnson et al. (15) in the $B M J$ a decade ago, the problem of weight status misperception persists in the United Kingdom. The persistence of the failure of individuals with overweight in weight recognition represents unsuccessful interventions of health professionals in tackling overweight and obesity (15). A close examination of demographic and socioeconomic characteristics associated with underestimation of weight status reveals social inequalities in weight misperception patterns. Among individuals with overweight or obesity, men and individuals with lower levels of education and income are more likely to underestimate their weight status and concomitantly less likely to try to lose weight. Members of minority ethnic groups are also more likely to underassess their weight status than the white population but do not necessarily have a lower chance of trying to lose weight. This type of exercise of identifying vulnerable subgroups of populations prone to misperceiving their weight status can help in designing obesity prevention strategies targeting specific needs of different groups.

The causes of socioeconomic inequalities in obesity, however, are fairly complex. Not only does access to health care services matter, but socioeconomic determinants related to living and working conditions and health literacy also substantially influence health and health behaviors (16). Likewise, the higher prevalence of overweight and obesity among individuals with lower levels of education and income may contribute to visual normalization, that is, more habitual visual exposure to people with excess weight than their counterparts with higher socioeconomic status have (6). To achieve effective public health intervention programs, it is therefore vital to prioritize inequities in overweight- and obesity-related risks. $O$

(C) 2018 The Authors. Obesity published by Wiley Periodicals, Inc. on behalf of The Obesity Society (TOS)

\section{References}

1. Cartner-Morley J. Plus-size reinvented: "We were told to hide, wear a sack - now we want equality." The Guardian. https://www.theguardian.com/fashion/2018/jan/ 09/plus-size-reinvented-curve-marks-and-spencer-range. Published January 9, 2018. Accessed January 19, 2018.

2. Almond K. Fashionably voluptuous: repackaging the fuller-sized figure. Fashion Theory 2013;17:197-222.

3. Kennedy K. What size am I? Decoding women's clothing standards. Fashion Theory 2009;13:511-530.

4. Aydinoğlu NZ, Krishna A. Imagining thin: why vanity sizing works. $J$ Consum Psychol 2012;22:565-572.

5. Duncan DT, Wolin KY, Scharoun-Lee M, Ding EL, Warner ET, Bennett GG. Does perception equal reality? Weight misperception in relation to weight-related attitudes and behaviors among overweight and obese US adults. Int J Behav Nutr Phys Act 2011;8:20. doi:10.1186/1479-5868-8-20.

6. Robinson E. Overweight but unseen: a review of the underestimation of weight status and a visual normalization theory. Obes Rev 2017;18:1200-1209.

7. Burke MA, Heiland FW, Nadler CM. From "overweight" to "about right": evidence of a generational shift in body weight norms. Obesity (Silver Spring) 2010;18:1226-1234.

8. Robinson E, Christiansen P. The changing face of obesity: exposure to and acceptance of obesity. Obesity (Silver Spring) 2014;22:1380-1386.

9. Robinson E, Haynes A, Sutin AR, Daly M. Telling people they are overweight: helpful, harmful or beside the point? Int J Obes (Lond) 2017;41:1160-1161.

10. Haynes A, Kersbergen I, Sutin A, Daly M, Robinson E. A systematic review of the relationship between weight status perceptions and weight loss attempts, strategies, behaviours and outcomes. Obes Rev 2018;19:347-363.

11. Organisation for Economic Co-operation and Development. Health at a Glance 2017: OECD Indicators. Paris: Organisation for Economic Co-operation and Development; 2017.

12. Allender S, Rayner M. The burden of overweight and obesity-related ill health in the UK. Obes Rev 2007;8:467-473.

13. Global BMI Mortality Collaboration; Di Angelantonio E, Bhupathiraju ShN, Wormser $\mathrm{D}$, et al. Body-mass index and all-cause mortality: individual-participant-data metaanalysis of 239 prospective studies in four continents. Lancet 2016;388:776-786.

14. Oyebode O, Mindell J. Use of data from the Health Survey for England in obesity policy making and monitoring. Obes Rev 2013;14:463-476.

15. Johnson F, Cooke L, Croker H, Wardle J. Changing perceptions of weight in Great Britain: comparison of two population surveys. BMJ 2008;337:a494. doi:10.1136/bmj.a494

16. Marmot M, Bell R. Social inequalities in health: a proper concern of epidemiology. Ann Epidemiol 2016;26:238-240. 